\title{
Prevalence of psychotropic medication use and association with challenging behaviour in adults with an intellectual disability. A total population study.
}

\section{Abstract \\ Background}

There is a high prevalence of psychotropic medication use in adults with Intellectual Disabilities (ID), often in the absence of psychiatric disorder, also associated with challenging behaviour. Previous research has focused on specific sample frames or data from primary care providers. There is also a lack of consistency in the definition of challenging behaviour used.

Methods

We adopted a total population sampling method. Medication data on 265 adults with ID were classified according to the Anatomical Therapeutic Chemical classification system. The Behavior Problems Inventory - short form measured challenging behaviours. We examined the association between challenging behaviour and the use of psychotropic medication, and whether any association would still be present after accounting for sociodemographic and clinical characteristics.

Results 
$70.6 \%$ of adults with ID were prescribed at least one medication (mean per person $=$ 2.62; range 0 -14). Psychotropic medications were used by $39.7 \%$ of participants with antipsychotics the commonest type used by $21.89 \%$ of individuals. Polypharmacy and high dosages were common. Generalised Linear Models indicated significant associations between psychotropic medication and the presence of a psychiatric diagnosis, challenging behaviour, older age and type of residence. Male gender was additionally associated with antipsychotic medication.

Conclusions

The use of a total population sample identified via multiple routes is less likely to under or overestimate prevalence rates of medication use. Current challenging behaviour was a predictor of medication use after controlling for other variables.

Keywords Psychotropic medication, antipsychotic, challenging behaviour, intellectual disability, Behavior Problems Inventory.

\section{Introduction}

There has been concern for a number of years that psychotropic medication, and in particular antipsychotic medication, is overused in people with intellectual disabilities (ID) (Deb \& Fraser, 1994; Sheehan et al. 2015). Studies have reported varied prevalence and patterns of prescribing. For example, UK estimates vary from $49 \%$ 
(Sheehan et al. 2015) to 89\% (Deb et al. 2014). Antipsychotics have been reported to be the most common type of medication prescribed to individuals with ID (Holden \& Gitlesen, 2004; Deb \& Unwin, 2007; Matson \& Neal, 2009; Singh \& Matson, 2009; Henderson et al. 2015; Sheehan et al. 2015). Research has also revealed that up to $62 \%$ of adults with ID who receive psychotropic medication receive multiple medications (Lott et al. 2004) often in high dosages (Cullen, 1999; McGillivary \& McCabe, 2004; Deb et al. 2009; Taylor, 2010). A high prevalence of psychiatric problems in adults with ID may explain some increased medication use (Chaplin, 2004; Cooper et al, 2007; Morgan et al. 2008; Buckles et al. 2013). However, high prescription rates may not be driven by the presence of psychiatric problems per se, but may be associated with the presence of challenging behaviour (Gothelf et al. 2008; Matson \& Neal, 2009; Henderson et al. 2015; Sheehan et al. 2015).

In studies that have used convenience or small samples recruited from clinical services, estimates of the prevalence of the use of psychotropic medication have been high. For example, in a community sample of adults with ID and aggressive behaviour in the West Midlands, UK, 89\% were prescribed psychotropic medication (Deb et al. 2014). Similarly, 72\% of adults with ID at a Psychiatry Department in Salford, UK, were prescribed antipsychotics (Griffiths et al. 2012). Data from such samples are likely to be associated with a range of biases and total population or population representative samples are needed. Henderson et al. (2015) focused on a prospective cohort sample of 1023 adults aged <16 years with ID known to local services including primary care (general practitioners - GPs) in Scotland. Sheehan et al. (2015) identified 32306 adults aged >18 years with ID from 3.7 million active patients on The Health Improvement Network (THIN). Records from 571 General Practices were examined where drug treatment for adults with ID was recorded from 
GP or secondary care specialists. Henderson et al. (2015) found a 49.1\% prevalence rate of psychotropic medication use with a prevalence rate of antipsychotic drug use of $23.2 \%$. Similarly, Sheehan et al. (2015) found a $49 \%$ prevalence of psychotropic medication use with $21 \%$ of participants prescribed antipsychotic medication. These studies used population-based samples, but identified their participants from primary and secondary care providers who were incentivised to provide data (2007; http://qof.hscic.gov.uk/).

Some studies have found that adults with challenging behaviour are prescribed more psychotropic medications than those without challenging behaviour (Holden \& Gitlesen, 2003; Aman \& Ramadan, 2007; Crossley \& Withers, 2009; Doan et al. 2013; Scheifes et al. 2015). In the Henderson et al. (2015) study, 32\% of those on antipsychotics had no mental health issues at the time of assessment. Sheehan et al. (2015) reported that $47 \%$ of participants with a record of challenging behaviour received antipsychotics but only $12 \%$ had a record of mental illness. There remains no convincing evidence of positive treatment effects of these medications on challenging behaviour (Emerson \& Baines, 2010; Tsiouris 2010; Paton et al. 2011; Wilner, 2014). The underlying aetiological factors for challenging behaviour are complex and varied (Hastings et al., 2013) so treatment with medication alone is unlikely to resolve the issue. Under current UK best practice guidelines (NICE, 2015; RCP, 2016) if adults with ID and challenging behaviour have no evidence of mental illness then there may be no role for prescribing, other than in the very short term to address risk as other psycho-social interventions are implemented.

Socio-demographic factors associated with higher prevalence rates of psychotropic medication are male gender (McGillivray \& McCabe, 2006; Delafon et al. 2013; Doan et al. 2014) and older age (Holden \& Gitlesen, 2004; Singh \& Matson, 
2009; Deb et al. 2014; Sheehan et al. 2015). Kiernan et al. (1995) found different prevalence rates in different districts of the UK and hypothesised that this may be due to different organisation in psychiatric services for people with ID. Variation in prevalence rates by residential setting has also been identified with highest prevalence rates in hospitals, lower in community residential services, and lowest in family homes (Clarke et al. 1990; Kiernan et al. 1995; Robertson et al. 2000; Tsiouris et al. 2013).

Further research is thus required for several reasons. First, obtaining accurate prevalence rates of psychotropic drug use has been problematic given many existing studies have focused on small, highly selective convenience samples with a lack of population wide estimates (Sheehan et al. 2015). The number of population-based studies is small with participants recruited predominantly from primary care. Second, there has been variation in results due to a lack of standardised medication rating systems, preventing comparisons between studies. For example, some researchers have included antiepileptics for epilepsy as psychotropic medications (Holden \& Gitlesen, 2004; Henderson et al. 2015), whereas other researchers have classed them as somatic medication (Scheifes et al. 2013; Doan et al. 2014).Third, researchers have used varied definitions of challenging behaviour to examine its putative association with medication use. Challenging behaviour may be better assessed through an individual assessment utilising a psychometrically evaluated behaviour rating scale with clear definitions of what constitutes challenging behaviour taking into account temporal and intensity factors.

The main aim of the present study was to address these limitations in existing evidence by investigating the prevalence of medication use, particularly psychotropic medication, in the total administrative population of adults with ID (identified through 
multiple methods) in Jersey, Channel Islands. We measured the prevalence of psychotropic medication using an internationally recognised coding system (the World Health Organisation Anatomic Therapeutic Classification Scheme - WHO, 2014; WHOCC - ATC/DDD, 2014) and examined associations with challenging behaviour identified by a rating tool with good psychometric properties (the Behavior Problems Inventory - short form; Rojahn et al. 2012a). We also explored whether any association between medication prescription and challenging behaviour would be present after accounting for other sociodemographic and clinical characteristics.

\section{Method}

\section{Participants}

Participants were 265 persons $\geq 18$ years of age administratively defined as having ID (i.e., who were receiving, or had received, support from services in Jersey). Participants were identified from multiple sources including the Health and Social Services (H\&SS) administrative database, in Jersey, FACE (Functional Analysis of Care Environments, http://www.face.eu.com). FACE is a database used by the local community multi-disciplinary ID service which includes social work, occupational therapy, community nursing, positive behaviour support service and physiotherapy. Records were cross-referenced with current Education Department Record of Needs, and records of individuals maintained by local service providers from the voluntary sector and employment support services. The population ascertainment process and more detail on the procedure is provided in a previous paper (Bowring 
et al. 2016). Table 1 summarises participant characteristics. Of the 265 participants $50.6 \%(n=134)$ were male and $49.4 \%(n=131)$ female with a mean age of 41.44 (range 18-85).

+++INSERT TABLE 1+++

\section{Procedure}

The study was approved by XXX University ethics committee, and by the States of Jersey, Health and Social Services ethics committee. The authors assert that all procedures contributing to this work comply with the ethical standards of the relevant national and institutional committees on human experimentation and with the Helsinki Declaration of 1975, as revised in 2008.

Researchers completed two surveys for each participant in face-to-face meetings with a proxy informant. Informants were either family members or key workers within a supporting organisation. Informants were judged to be in a good position to provide information about the participant if they had a minimum of regular weekly contact and had known the participant for at least one year. All data were collected over a period of 12 months.

\section{Measures}

\section{Medication data}


The first survey tool was adapted from the Individual Schedule of the Challenging Behaviour Survey (Alborz et al. 1994) and the Wessex Scale (Kushlick et al. 1973; Palmer \& Jenkins, 1982) to collect socio-demographic information and clinical characteristics including medication use. Medication data collected included name of medication and corresponding dosage. For adults living in paid and congregate care settings $(n=132)$ data were taken directly from individual Medication Administration Record (MAR). For adults who lived independently or with family, medication use data were provided by proxy informants $(n=133)$.

Medication use was coded according to the World Health Organisation Anatomic Therapeutic Chemical (ATC) Classification scheme (WHO, 2014; WHOCC - ATC/DDD, 2014). This system has been used in other studies of medication use in individuals with ID (Scheifes et al. 2013; Doan et al. 2014). The ATC system groups medications into 14 categories according to the organs or system on which they act or their chemical, pharmacological or therapeutic characteristics (Doan et al. 2014). Medication was independently coded by an Intellectual Disability Nurse, with research experience, who was an independent and supplementary prescriber (v300 Qualification). Psychotropic medications were defined as medical agents for the nervous system, excluding analgesics and antiepileptics prescribed for epilepsy (Doan et al. 2014). Psychotropic medications included anticholinergic agents, antipsychotics, anxiolytics, hypnotics and sedatives, antidepressants, psychostimulants and antiepileptics used as mood stabilisers.

All medication listed on the surveys was initially checked to ensure they were listed using their generic name (active ingredient) rather than trade name. Medication was entered into the electronic Medicines Compendium (https://www.medicines.org.uk/emc/) to establish the generic name of all medication 
reported in surveys. All medication, using the generic name, was then entered into the WHO database (http://www.whocc.no/atc ddd index/) to establish the automated ATC code for that medication. There were several cases where there were different codes for particular medicines depending on their purpose of pharmacology. In 11 cases the research team had to return to proxy informants, or the health service database (FACE), to establish medical history and the pharmacological purpose of the medicine. There were 6 medications listed under 'various - others not classified' where there was no code listed under the ATC system; these were vitamin based products or creams with no active ingredients. Of the 68 people who were using antiepileptics, 15 did not have a diagnosis of epilepsy or history of seizures when checked against the demographic data. Researchers returned to proxy informants or the FACE database to check the purpose of the pharmacology. In some instances proxy informants checked with prescribers general practitioners or psychiatrists. It was discovered that 5 people were prescribed antiepileptics as a result of historical investigations into potential absence seizures, 3 were receiving the medication for nerve pain and 7 as mood stabilisers. For these latter 7 people we included the use of antiepileptics as mood stabilisers in the psychotropic drug category as per previous studies (Scheifes et al. 2013). Antiepileptics prescribed for epilepsy (and suspected epilepsy) or pain were categorised under the somatic label.

For each medication, the ATC also provides a defined daily dose (DDD) which is in effect an average daily dosage for its main indication. Dosage was investigated for medication which affected the nervous system ( $\mathrm{N}$-coded) which included psychotropic medication. In this study, we recorded dosage against the listed DDD as below the DDD, equivalent to the DDD, or above the DDD. There were 3 
medication entries within the nervous system category which researchers could not code. Lithium (x2) dosage is coded as 24 millimoles per litre as clinicians take bloods prior to placing people on lithium to establish serum levels in the blood, against which then they work out dosage. Nicotine patches $(x 1)$ had numerous dosages depending on type so researchers were also unable to code that.

All coded medication data were then independently checked by another researcher. There were two data entry errors - out of 694 medication entries - and these were amended. Prevalence was then calculated for all medications. The independent coder then categorised all medication within the four digit ATC code to create a table of prevalence according to the class of the medication (see Table 2).

\section{Challenging behaviour data}

Researchers also completed the Behavior Problems Inventory - short form (BPI-S) (Rojahn et al. 2012ab; Mascitelli et al. 2015) to measure challenging behaviour during the previous six months as reported by proxy informants. BPI-S data were coded against the following definition (Bowring et al. 2016):

a) SIB: any item of self-injurious behaviour is "challenging" if either it is rated as severe and occurs at least weekly, or is rated as moderate but occurs at least daily. Any other occurrence of behaviour is not rated as challenging.

b) ADB: any item of aggressive destructive behaviour is "challenging" if either it is rated as severe and occurs at least weekly, or is rated as moderate but occurs at least daily. Any other occurrence of behaviour is not rated as challenging. 
c) SB: any item of stereotyped behaviour is "challenging" if it occurs at the highest rated frequency (hourly). Any other occurrence of behaviour is not rated as challenging.

d) CB: Overall challenging behaviour is defined by the presence of a least one behaviour defined as "challenging" in the above categories.

The overall prevalence of challenging behaviour was $18.1 \%$ (95\% Cl: $13.94 \%-$ 23.19\%; $n=48)$, self-injurious behaviour was 7.5\% (95\% Cl: 4.94\%-11.37\%; $n=20)$, aggressive and destructive behaviour $8.3 \%(95 \% \mathrm{Cl}: 5.54 \%-12.25 \%$; $n=22)$, and stereotyped behaviour 10.9\% (95\% Cl: 7.73\%-15.27\%; $n=29)$ (Bowring et al. 2016).

\section{Statistical Analysis}

Descriptive statistics were used to summarise the overall prevalence of medication use in the sample. We then investigated the association between challenging behaviour (total challenging behaviour, aggressive and destructive behaviour, self-injury and stereotypy) and medication using Chi Square associations, additionally estimating unadjusted Relative Risks (RR). Finally, we adjusted for other variables using multivariable Generalised Linear Models (GLM) to further explore the association between medication use and challenging behaviour.

\section{Results}

\section{Medication prevalence}


+++INSERT TABLE 2+++

Table 2 shows the prevalence of medication use within this sample. A total of $70.6 \%$ ( $n=187)$ adults with ID were prescribed at least one medication (mean=2.62; range $0-14)$. Under the ATC system the largest group of medications used was those coded to treat the nervous system used by $52.07 \%(n=138)$, followed by those for alimentary tract and metabolism used by $31.32 \%(n=83)$, followed by drugs for the cardiovascular system used by $15.69 \%(n=40)$.

Within the total sample $37.73 \%(n=100$; mean $=.68$; range $0-5)$ used a psychotropic medication. The largest group of psychotropic medications used were antipsychotic medications used by $21.89 \%(n=58$; mean $=.27$; range $0-3)$. Most commonly used were second generation (atypical) antipsychotics used by $15.09 \%$ $(n=40)$. Of these the most common medications were Risperidone $(n=16)$ and Olanzapine ( $n=13)$. Of the first generation (typical) antipsychotics used by $7.92 \%$ $(n=21)$, the most common drug used was Haloperidol $(n=10)$. The second largest group of psychotropic medications was antidepressants used by $17.38 \%$ ( $n=46$; mean number=.18; range $0-2$ ). The majority of these were selective serotonin reuptake inhibitors (SSRI) antidepressants used by $12.83 \%(n=34)$. The most common SSRI drugs used were Citalopram $(n=10)$, Paroxetine $(n=7)$ and Fluoxetine $(n=6)$.

\section{Dosage and polypharmacy}


Nearly one-third of participants who were prescribed medication for the nervous system were prescribed at a level above the DDD: $30.43 \%(n=42)$ used at least one medication above the DDD (35 people took one medication above DDD, 6 people 2 medications above DDD, 1 person 3 medications above DDD).

Among those prescribed medication for the nervous system ( $n=138) 41.31 \%$ were prescribed just one medication, while $58.69 \%$ were prescribed $2+$ medications (mean $=3.20$; range 2-5). Polypharmacy was also common with psychotropic medication. Among those prescribed psychotropic medication ( $n=100), 51 \%$ were prescribed just one medication, while $49 \%$ were prescribed $2+$ medications (mean=3.69; range 2-5).

\section{Bivariate Analysis of the challenging behaviour-psychotropic medication} association

+++INSERT TABLE 3+++

Chi-square tests were used to explore the association between challenging behaviour (total challenging behaviour, aggressive and destructive behaviour, selfinjury and stereotypy) and medication use. Table 3 summarises these associations by detailing the percentage in the challenging behaviour and no challenging behaviour groups prescribed medication. Where associations were statistically significant at $p<.05$ we supplemented the chi-square results with a Relative Risk (RR) described below. 
Adults with challenging behaviour were nearly twice as likely to be prescribed psychotropic medication compared to adults who did not present challenging behaviour ( $\mathrm{RR}=1.921,95 \% \mathrm{Cl}: 1.328$ to 2.781$)$. Similarly, adults who displayed aggressive and destructive behaviour were nearly two times more likely to have been prescribed psychotropic medication ( $\mathrm{RR}=1.891 ; 95 \% \mathrm{Cl}: 1.207$ to 2.965$)$. The adults with self-injurious behaviour were more than two and a half times as likely to have psychotropic medications prescribed ( $R R=2.606 ; 95 \% \mathrm{Cl}=1.741$ to 3.902$)$. There was no significant association between stereotypical behaviour and psychotropic medication use.

Adults with challenging behaviour were nearly three times as likely to have been prescribed antipsychotic medication compared adults who did not present challenging behaviour ( $R R=2.99 ; 95 \% \mathrm{Cl}: 1.524$ to 5.869$)$. Similarly, adults with stereotypical behaviour were nearly two and a half times as likely to use antipsychotic medication ( $R R=2.457 ; 95 \% \mathrm{Cl}: 1.087$ to 5.553$)$. Adults with selfinjurious behaviour were more than four times as likely to use antipsychotic medication ( $\mathrm{RR}=4.104 ; 95 \% \mathrm{Cl}: 1.617$ to 10.418$)$. There was no association between aggressive destructive behaviour and antipsychotic drug use.

There was no association between antidepressant medication use and any topography of challenging behaviour.

\section{Multivariate analysis of the challenging behaviour-psychotropic medication association}

In the final analyses, we wanted to explore whether the associations between challenging behaviour and medication use remained after accounting for potential 
correlates of medication use. To identify correlates, we first ran a simple generalised linear model (GLM) to obtain an unadjusted RR between the potential correlate (sociodemographic and other clinical characteristics) and the use of medication variables. Variables considered were psychiatric diagnosis, age, gender, type of residence (living in paid/congregate care versus other), degree of ID (severe/profound versus mild/moderate), low communication skills (non-verbal or no clear speech and limited receptive understanding) and sensory impairments (sight or hearing impairment). All correlates significantly associated with medication use were then fitted into a multivariable GLM to examine all potentially relevant correlates alongside challenging behaviour.

GLMs were used to explore the association with the number of psychotropic medications used $(0,1,2,3+)$ fitted to follow a Poisson distribution with robust standard errors (Knoll et al. 2012). For a number of antipsychotic medications (defined as 0 and 1+) we fitted a logistic GLM. Results are presented in tables 4 and 5.

+++INSERT TABLE 4+++ +++INSERT TABLE 5+++

Results from GLM Poisson regression models showed that those with a psychiatric diagnosis had a $4.22 \mathrm{RR}(95 \% \mathrm{Cl} 3.007$ to $5.92 ; \mathrm{p}<.001)$ of being prescribed psychotropic medication (Table 4). Those living in paid or congregate care had a $2.015 \mathrm{RR}(95 \% \mathrm{Cl} 1.378$ to 2.946 ; $\mathrm{p}<.001)$; those who presented challenging behaviour a $1.921 \mathrm{RR}(95 \% \mathrm{Cl} 1.328$ to $2.781 ; \mathrm{p}<.001)$; adults with a severe profound ID a $1.475 \mathrm{RR}(95 \% \mathrm{Cl} 1.009$ to $2.155 ; \mathrm{p}=.045)$; and (older) age 
gave a $1.034 \mathrm{RR}(95 \% \mathrm{Cl} 1.025$ to $1.044 ; \mathrm{p}<.001)$. There were no significant associations between gender, sensory impairment or low communication skills and the use of psychotropic medication. When all significantly associated variables were entered in the GLM model together (Table 5), severe-profound ID was no longer significantly associated with psychotropic use. Significant correlates remaining included psychiatric disorder ( $R R=3.725 ; 95 \% \mathrm{Cl} 2.68$ to $5.178 ; p<.001)$, challenging behaviour ( $R R=1.565 ; 95 \% \mathrm{Cl} 1.074$ to $2.282 ; p=.02)$, living in paid/congregate care $(R R=1.542 ; 95 \% \mathrm{Cl} 1.082$ to $2.196 ; p=.016)$ and (older) age $(R R=1.023 ; 95 \% \mathrm{Cl}$ 1.013 to $1.034 ; \mathrm{p}<.001)$.

Using GLM loglink regression models we found that those with a psychiatric diagnosis had a $7.478 \mathrm{RR}(95 \% \mathrm{Cl} 3.945$ to $14.174 ; \mathrm{p}<.001)$ of using antipsychotic medication (Table 4). Those who presented with challenging behaviour had a 2.99 $\mathrm{RR}(95 \% \mathrm{Cl} 1.524$ to $5.869 ; \mathrm{p}=.001)$; those living in paid / congregate care a 2.516 $\mathrm{RR}(95 \% \mathrm{Cl} 1.363$ to $4.644 ; \mathrm{p}=.003)$; males had a $2.42 \mathrm{RR}(95 \% \mathrm{Cl} 1.311$ to 4.466 ; $p=.005)$; those with a severe/profound ID a $2.099 \mathrm{RR}(95 \% \mathrm{Cl} 1.096$ to 4.019 ; $\mathrm{p}=.025)$; and (older) age a $1.05 \mathrm{RR}(95 \% \mathrm{Cl} 1.03$ to $1.071 ; \mathrm{p}<.001)$. There was no significant association between sensory impairments and low communication skills and antipsychotic medication use. When all significant correlates were entered into the model together (Table 5), living in paid/congregate care and severe/profound ID were no longer significant. Significantly correlates remaining were psychiatric disorder ( $R R=9.124 ; 95 \% \mathrm{Cl} 4.151$ to $20.058 ; p<.001)$, male gender $(R R=3.35 ; 95 \%$ Cl 1.573 to $7.134 ; p=.002)$, challenging behaviour $(R R=2.968 ; 95 \% \mathrm{Cl} 1.131$ to 7.79 ; $\mathrm{p}=.027)$ and (older) age ( $\mathrm{RR}=1.043 ; 95 \% \mathrm{Cl} 1.018$ to $1.069 ; \mathrm{p}=.001)$. 


\section{Discussion}

Among the total administrative population of adults with ID in Jersey, nearly 4 in 10 were in receipt of at least one psychotropic medication $(37.73 \%, n=100)$ and $30.43 \%,(n=42)$ were prescribed a medication which acts on the nervous system above the indicated daily dose. Nearly half of all adults prescribed psychotropic medications $(49 \%, n=49)$ were in receipt of more than one of these medications. Thus, the use of psychotropic medication, at high doses and polypharmacy were common supporting previous evidence (Deb et al. 2014; Henderson et al. 2015; Sheehan et al. 2015).The most prevalent group of medications was antipsychotics, prescribed to $21.89 \%$ of people. This confirms the preference for this type of medication by prescribers as seen in other studies (Holden \& Gitlesen, 2004; Deb \& Unwin, 2007; Matson \& Neal, 2009; Singh \& Matson, 2009). Second generation antipsychotics were used by $15.09 \%$ of the sample which confirms a shift in prescribing patterns to second generation antipsychotics and SSRIs (Spreat et al. 2004; Matson \& Neal, 2009; Paton et al. 2011).

The prevalence of psychotropic drug use is lower in our sample than those reported from other recent studies in the UK (e.g. Henderson et al. 2015, 49.1\%; Sheehan et al. 2015, 49\%). There are a number of potential reasons for this. First, one strength of this population study was that it did not recruit from a particular clinical route such as participants in contact with general practitioners and psychiatrists (e.g. Henderson et al. 2015; Sheehan et al. 2015). People in contact with prescribers, especially those in contact with secondary care may have greater psychiatric and behavioural issues, thus overestimating the prevalence of 
psychotropic prescribing in adults with ID. The total population ascertainment process here ensured participants came from multiple routes including the Health and Social Service database FACE (223 people), Education (6 people), voluntary sector (16 people) and employment support services (20 people). There may be potentially lower prevalence estimates in studies that consider population samples from family or community living samples and not just specialised challenging behaviour, residential, or hospital services.

Second, this study did not recruit from one specific clinical setting like other studies with high prevalence rates (e.g. Griffiths et al. 2012, 72\%; Deb et al. 2014, $89 \%)$. We found the prevalence of antipsychotics by residence was $11 \%$ for those residing in family homes, $21.4 \%$ in independent living and $29.5 \%$ in paid/congregate care. Studies that have considered differing prescribing patterns by setting have found similar variation (Kiernan et al. 1995; Roberston et al. 2000).

Third, previous studies have identified regional variations in prevalence rates between districts of origins in the UK (Kiernan et al. 1995). This has been explained by the fact that prescribing professionals, practices and samples will vary by region. Sheehan et al. (2015) reported a $21 \%$ prevalence of antipsychotics and $20 \%$ prevalence of antidepressants which was similar to the present sample $(21.89 \%$ and $17.36 \%)$, but a higher prevalence of mood stabilisers (20\%) and anxiolytics/hypnotics (22\%) compared to the present sample (2.64\% and $10.57 \%)$. There appears to be less use of these specific medications in Jersey. The Jersey General Hospital Formulary (States of Jersey, 2016) may detail a different set of medications to other authorities/countries and identifies some medications primary care providers (GPs) cannot prescribe. 
In Jersey, all adults with ID and challenging behaviour are open to the ID service psychiatrist. Some evidence has suggested a reduced level of prescribing from psychiatrists compared to GPs (Holden \& Gitlesen, 2004). We found that 39.7\% of adults with ID in receipt of antipsychotic medication did not have a psychiatric disorder. This rate is lower than that reported in other recent studies $(50-71 \%$ : Tsiouris, 2010, Paton et al. 2011; Marston et al. 2014; Sheehan et al. 2015). Further investigations are required into regional variations and what influences prescribing patterns of individual medications at a prescriber level.

Our data also suggested that antipsychotic (but not antidepressant) medication prescribed in the absence of a psychiatric diagnosis may be related to the presence of challenging behaviour. Ascertainment of the presence of challenging behaviour was a strength of the current study through the BPI-S (Rojahn et al. 2012ab; Macitelli et al. 2015). Our data extended previous findings (Brylewski \& Duggan, 2004; Tsiouris, 2010; Henderson et al. 2015; Sheehan et al. 2015) by indicating different patterns of association with specific topographies of challenging behaviour. In particular, psychotropic medication use was associated with aggressive/destructive behaviour and self-injurious behaviour, but not stereotyped behaviour. Antipsychotic medication use was associated with self-injurious behaviour and stereotyped behaviour, but not aggressive/destructive behaviour. It is of interest that antipsychotic use was associated with behaviours that could be considered inner-directed (self-injury and stereotypy), but not outward-directed such as aggression/destruction. In the presence of aggression/destruction the relative risk of using hypnotics/sedatives was over $200 \%$ and $700 \%$ for using antiepileptics as mood stabilisers. Overall, our data indicate that differences in prescribing patterns may be 
associated with specific challenging behaviours, or the features associated with those behaviours.

Factors other than challenging behaviour and psychiatric diagnosis were also associated with medication use in the present study after controlling for all other examined variables. Psychotropic medication use was additionally associated with living in paid/congregate care and increased age. Antipsychotic medication was similarly associated with increased age and also male gender. Associations between psychotropic medication use, older age, and type of residence have been seen consistently in other studies (Aman, Sarphare \& Burrow, 1995; Kiernan et al. 1995; Singh et al. 1997; Robertson et al. 2000; Holden \& Gitlesen, 2004; Sheehan et al. 2015). The increased likelihood of receiving antipsychotic medication for males compared to females has also been reported in other studies and requires further exploration to consider why this is (McGillivray \& McCabe, 2006; Delafon et al. 2013; Doan et al. 2014).

A limitation of the present study is that findings apply only to the administratively defined ID population in Jersey while there may also be adults with ID $<70$ not known to services who were not included. However, those with greater support needs may be more likely to be known to services. A second limitation was the reliance on proxy informants to report medication use for those living in family or independent settings (133 participants) where there is a possibility of misreporting as these informants are not clinically trained. However, potential inaccuracy was limited as proxy informants often showed researchers the medication with listed name and dosage; where they were unsure they made further enquiries and researchers contacted them again. Follow up checks were also made on the FACE database as 
initial assessments, care plans and nursing plans listed on FACE usually contained information on medication use.

\section{References}

Alborz A., Bromley J., Emerson E., Kiernan C. \& Qureshi H. (1994) Challenging behaviour survey: Individual schedule. Manchester: Hester Adrian Research Centre, University of Manchester.

Aman M. G., Sarphare G. \& Burrow W. (1995) Psychotropic drugs in group homes: prevalence and relation to demographic/psychiatric variables. American Journal of Mental Retardation 99, 500-9.

Aman M. G. \& Ramadan Y. (2007). Pharmacotherapy. In J. W. Jacobson, J. A. Mulick \& J. Rojahn (Eds.), Handbook of intellectual and developmental disabilities. Issues in clinical child psychology (pp. 657-671). New York, NY: Springer Publishing Co.

Bowring D. L., Totsika V., Hastings R. P., Toogood S. \& Griffiths G. M. (2016) The prevalence and correlates of challenging behaviour in the administrative population of adults with an intellectual disability in Jersey. Under Review.

British National Formulary - BNF (70), Sept 2015 - March 2016. www.bnf.org

Buckles J., Luckasson R. \& Keefe E. (2013) A systematic review of the prevalence of psychiatric disorders in adults with intellectual disability, 2003-2010. Journal of Mental Health Research in Intellectual Disabilities 6, 181-207. DOI:10.1080/19315864.2011.651682

Brylewski J. \& Duggan L. (2004) Antipsychotic medication for challenging behaviour in people with learning disability. Cochrane Database Systematic Review, Issue 3. Art. No.: CD000377. DOI:10.1002/14651858.CD000377.pub2

Chaplin R. (2004) General psychiatry services for adults with intellectual disabilities and mental illness. Journal of Intellectual Disability Research 48, 1-10. DOI:10.1111/j.1365-2788.2004.00580.x

Clarke D. J., Kelley S., Thinn K. \& Corbett J. A. (1990) Psychotropic drugs and mental retardation: 1. Disabilities and the prescription of drugs for behaviour and for epilepsy in three residential settings. Journal of Mental Deficiency Research 34, 385-395. DOI:10.1111/j.1365-2788.1990.tb01549.x

Cooper S-A., Smiley E., Morrison J., Williamson A. \& Allan L. (2007) Mental illhealth in adults with intellectual disabilities: prevalence and associated factors. British Journal of Psychiatry 190, 27-35. DOI:10.1192/bjp.bp.106.022483 
Crossley R. \& Withers P. (2009) Antipsychotic medication and people with intellectual disabilities: Their knowledge and experiences. Journal of Applied Research in Intellectual Disabilities 22, 77-86. DOI:10.1111/j.14683148.2008.00454.x

Cullen C. (1999) A review of Some Important Issues in Research and Services for People with Learning Disabilities and Challenging Behaviour. https://www.researchgate.net/publication/254859326_A_Review_of_Some_Im portant_Issues_in_Research_and_Services_for_People_with_Learning_Disa bilities_and_Challenging_Behaviour.

Deb S. \& Fraser W. I. (1994) The use of psychotropic medication in people with I earning disability: Towards rational prescribing. Human Psychopharmacology, 9, 259-272. DOI:10.1002/hup.470090405

Deb S. \& Unwin G. L. (2007) Psychotropic medication for behavior problems in people with intellectual disability: A review of the current literature. Current Opinion in Psychiatry 20, 461-466. DOI:10.1097/YCO.0b013e3282ab9952

Deb S., Kwok H., Bertelli M., Salvador-Carulla L., Bradley E., Torr J. et al. (2009) International guide to prescribing psychotropic medication for the management of problem behaviours in adults with intellectual disabilities. World Psychiatry 8, 181-6. DOI:10.1002/j.2051-5545.2009.tb00248.x

Deb S., Unwin G. \& Deb T. (2014) Characteristics and the trajectory of psychotropic medication use in general and antipsychotics in particular among adults with ID who exhibit CB. Journal of Intellectual Disability research 59, 11-25. DOI:10.1111/jir.12119

Delafon V., Kiani R., Barrett M., Vahabzadeh A., Vaidya H., Walker W. et al. (2013) Use of PRN medication in people with intellectual disabilities, Advances in Mental Health and Intellectual Disabilities 7, 346-355. DOI:org/10.1108/AMHID-05-2013-0032

Doan T. N., Lennox N. G., Taylor-Gomez M. \& Ware R. S. (2013) Medication use among Australian adults with intellectual disability in primary health care settings: a cross sectional study. Journal of Intellectual and Developmental Disability 38, 177-81. DOI:10.3109/13668250.2013.778968

Doan T., Ware R., McPherson L., van Dooren K., Bain C., Carrington S. et al. (2014) Psychotropic medication use in adolescents with intellectual disability living in the community. Pharmacoepidemiology and drug safety 23: 69-76. DOI:10.1002/pds.3484

Emerson E. \& Baines S. (2010) Health Inequalities and People with Learning Disabilities in the UK: 2010. Durham: Improving Health \& Lives: Learning Disabilities Observatory. 
Gothelf D., Goraly O., Avni S., Stawaski M., Hartmann I., Basel-Vanagaite L. et al. (2008) Psychiatric morbidity with focus on obsessive-compulsive disorder in an Israeli cohort of adolescents with mild to moderate mental retardation. Journal of Neural Transmission 115, 1435-1463. DOI:10.1007/500702-0080037-4

Griffiths H., Halder N. \& Chaudhry N. (2012) Antipsychotic prescribing in people with intellectual disabilities: a clinical audit, Advances in Mental Health and Intellectual Disabilities 6, 215-222. DOI.org/10.1108/20441281211236661

Hastings R. P., Allen D., Baker P., Gore N. J., Hughes J. C., McGill P. et al. (2013) A conceptual framework for understanding why challenging behaviours occur in people with developmental disabilities. International Journal of Positive Behavioural Support 3, 5-13.

Henderson A., Kinnear D., Morrison J., Allen L. \& Cooper S-A. (2015) Psychotropic drug prescribing in a cohort of adults with intellectual disabilities in Scotland. Presented at the Seattle Club Conference, Cardiff, December $11^{\text {th }} 2015$.

Holden B. \& Gitlesen J. P. (2003). Prevalence of psychiatric symptoms in adults with mental retardation and challenging behaviour. Research in Developmental Disabilities 24, 323-332. DOI:10.1016/S0891-4222(03)00060$\mathrm{X}$

Holden B. \& Gitlesen J. P. (2004) Psychotropic medication in adults with mental retardation: prevalence, and prescription practices. Research in Developmental Disabilities 25, 509-21. DOI:10.1016/j.ridd.2004.03.004

Kiernan C., Reeves D. \& Alborz A. (1995) The use of anti-psychotic drugs with adults with learning disabilities and challenging behaviour. Journal of Intellectual Disability Research 39, 263-274. DOI:10.1111/j.13652788.1995.tb00518.x

Knoll M. J., Le Cessie S., Algra A., Vandenbroucke J. P. \& Groenwold R. H. H. (2012) Overestimation of risk ratios by odds ratios in trials and cohort studies: alternatives to logistic regression. Canadian Medical Association Journal 184, 895-899.

Kushlick A., Blunden R. \& Cox G. (1973). A method of rating behaviour characteristics for use in large scale surveys of mental handicap. Psychological Medicine 3, 466-478. DOI:org/10.1017/S0033291700054271

Lott I. T., McGregor M., Engelman L., Touchette P., Tournay A., Sandman C. et al. (2004) Longitudinal prescribing patterns for psychoactive medications in community-based individuals with developmental disabilities: utilization of pharmacy records. Journal of Intellectual Disability Research 48, 563-571. DOI: $10.1111 / \mathrm{j} .1365-2788.2004 .00625 . x$ 
Marston L., Nazareth I., Petersen I., Walters K. \& Osborn D. P. (2014) Prescribing of antipsychotics in UK primary care: a cohort study. British Medical Journal, Open e006135. DOI:10.1136/bmjopen-2014-006135

Mascitelli A. N., Rojahn J., Nicolaides V. C., Moore L., Hastings R. P. \& ChristianJones, C. (2015) The Behavior Problems Inventory - Short Form (BPI-S): reliability and factorial validity in adults with intellectual disabilities. Journal of Applied Research in Intellectual Disabilities 28, 561-571. DOI:10.1111/jar.12152

Matson J. L. \& Neal. D. (2009) Psychotropic medication use for CB's in persons with ID. An overview. Research in Developmental Disabilities 30, 572-586. DOI:10.1016/j.ridd.2008.08.007

McGillivray J. A. \& McCabe M. P. (2006) Emerging trends in the use of drugs to manage challenging behaviour in people with intellectual disability. Journal of Applied Research in Intellectual Disability 19, 163-172. DOI:10.1111/j.14683148.2005.00251.x

Morgan V. A., Leonard H., Bourke J. \& Jablensky A. (2008) Intellectual disability cooccurring with schizophrenia and other psychiatric illness: population-based study. British Journal of Psychiatry 193, 364-72. DOI:10.1192/bjp.bp.107.044461

NICE guidelines [NG11]. (2015) Challenging behaviour and learning disabilities: prevention and interventions for people with learning disabilities whose behaviour challenges.

https://www.nice.org.uk/guidance/ng11. Accessed 24th October 2015.

Palmer J. \& Jenkins J. (1982) The 'Wessex' behaviour rating system for mentally handicapped people: Reliability study. British Journal of Mental Subnormality 28, 88-96. DOI:10.1179/bjms.1982.011

Paton C., Flynn A., Shingleton-Smith A., Mcintyre S., Bhaumik S., Rasmussen J. et al. (2011) Nature and quality of antipsychotic prescribing practice in UK psychiatry of intellectual disability services. Journal of Intellectual Disability Research 55, 665-674. DOI:10.1111/j.1365-2788.2011.01421.x

Robertson J., Emerson E., Gregory N., Hatton C., Kessissoglou S. \& Hallam A. (2000) Receipt of psychotropic medication by people with intellectual disability in residential settings. Journal of Intellectual Disability Research 44, 666-676. DOI:10.1111/j.1365-2788.2000.00307.x

Rojahn J., Rowe E. W., Sharber A. C., Hastings R., Matson J. L., Didden R., Kroes D. B. H. \& Dumont E. L. M. (2012a) The Behavior Problems Inventory-Short Form for individuals with intellectual disabilities: Part I: development and provisional clinical reference data. Journal of Intellectual Disability Research 56, 527-545. DOI:10.1111/j.1365-2788.2011.01507.x 
Rojahn J., Rowe E. W., Sharber A. C., Hastings R., Matson J. L., Didden R., Kroes D. B. H. \& Dumont E. L. M. (2012b) The Behavior Problems Inventory-Short Form for individuals with intellectual disabilities: Part II: reliability and validity. Journal of Intellectual Disability Research 56, 546-565. DOI:10.1111/j.13652788.2011.01506.x

Royal College of Psychiatrists (2016) Psychotropic drug prescribing for people with intellectual disability, mental health problems and/or behaviours that challenge: practice guidelines. Faculty report FR/ID/09. http://www.rcpsych.ac.uk/pdf/FDR ID 09 for website.pdf Accessed 22nd April 2016.

Scheifes A. , de Jong D., Stolker J. J., Nijman H. L., Egberts T. C. \& Heerdink E. R. (2013) Prevalence and characteristics of psychotropic drug use in institutionalised children and adolescents with mild ID. Research in Developmental Disabilities 34, 3159-3167. DOI:10.1016/j.ridd.2013.06.009

Scheifes A., Egberts T. C. G., Stolker J. J., Nijman Henk L. I. \& Heerdink E. R. (2015). Structured Medication Review to Improve Pharmacotherapy in People with Intellectual Disability and Behavioural Problems. Journal of Applied Research in Intellectual Disabilities. DOI:10.1111/jar.12183.

Sheehan R., Hassiotis A., Walters K., Osborn D., Strydom A. \& Horsfall C. (2015) Mental illness, challenging behaviour, and psychotropic drug prescribing in people with intellectual disability: UK population based cohort study. British Medical Journal, 2015;351:h4326. DOI:org/10.1136/bmj.h4326

Singh N. N., Ellis C. R. \& Wechsler H. (1997) Psychopharmacoepidemiology of mental retardation. 1966 to 1995, Journal of Child and Adolescent Psychopharmacology 7, 255-267. DOI:10.1089/cap.1997.7.255.

Singh A. N. \& Matson J. L. (2009). An examination of psychotropic medication prescription practices for individuals with intellectual disabilities. Journal of Developmental and Physical Disabilities 21, 115-129. DOI:10.1007/s10882008-9129-1

Spreat S., Conroy J. W \& Fullerton A. (2004) Statewide longitudinal survey of psychotropic medication use for persons with mental retardation: 1994 to 2000. American Journal on Mental Retardation 109, 322-331. DOI:10.1352/0895-8017

States of Jersey (2016). Jersey General Hospital Formulary. https://soj/depts/HSS/Registered\%20Documents/Jersey\%20General\%20Hos pital\%20Formulary\%20update\%20Mar\%202016\%20version\%201.pdf\#search =general\%20hospital\%20formulary

Taylor D. (2010) Antipsychotic polypharmacy-confusion reigns. The Psychiatrist 34, 41-3. DOI:10.1192/pb.bp.109.027086 
Tsiouris J. A. (2010) Pharmacotherapy for aggressive behaviours in persons with intellectual disabilities: treatment or mistreatment? Journal of Intellectual Disabilities Research 54, 1-16. DOI:10.1111/j.1365-2788.2009.01232.x

Tsiouris J.A., Kim S. Y., Brown W. T., Pettinger J. \& Cohen I. L. (2013) Prevalence of psychotropic drug use in adults with intellectual disability: Positive and negative findings from a large scale study. Journal of Autism and Developmental Disorders 43, 719-731.DOI:10.1007/s10803-012-1617-6

WHO Collaborating Centre for Drug Statistics Methodology. (2014) Guidelines for ATC classification and DDD assignment. Oslo, 2013.

WHOCC - ATC/DDD index (2014), from http://www.whocc.no/atc_ddd_index/.

Wilner, P. (2014) The neurobiology of aggression: implications for the pharmacotherapy of aggressive CB by people with ID. Journal of Intellectual Disability Research 59, 82-92. DOI:10.1111/jir.12120 
Table 1. Characteristics of participants

\begin{tabular}{|c|c|}
\hline Characteristic & Summary statistic \\
\hline Mean age in years (SD) & $41.44(16.278)$ \\
\hline \multirow{2}{*}{ Gender } & Male: $134(50.6 \%)$ \\
\hline & Female: $131(49.4 \%)$ \\
\hline \multirow[t]{4}{*}{ Type of accommodation } & Congregate care: 108 (40.8\%) \\
\hline & Paid carer: $24(9.1 \%)$ \\
\hline & Family carer: 91 (34.3\%) \\
\hline & Independent living: 42 (15.8\%) \\
\hline \multirow[t]{5}{*}{ Time in setting } & Less than 1 year: $32(12.1 \%)$ \\
\hline & $1-5$ years: $60(22.6 \%)$ \\
\hline & $6-10$ years: $62(23.4 \%)$ \\
\hline & $11-20$ years: $53(20 \%)$ \\
\hline & 21 years plus: $58(21.9 \%)$ \\
\hline \multirow[t]{4}{*}{ Degree of intellectual disability } & Profound: $26(9.8 \%)$ \\
\hline & Severe: $32(12.1 \%)$ \\
\hline & Moderate: 83 (31.3\%) \\
\hline & Mild: 124 (46.8\%) \\
\hline \multirow[t]{7}{*}{ Other diagnoses (include) } & Autism: 31 \\
\hline & Down Syndrome: 36 \\
\hline & Cerebral Palsy: 15 \\
\hline & ADHD: 2 \\
\hline & Fragile X: 2 \\
\hline & Soto syndrome: 2 \\
\hline & Other: 11 \\
\hline \multirow[t]{6}{*}{ Daytime engagement } & Paid work: 37 (14\%) \\
\hline & Voluntary work: 39 (14.7\%) \\
\hline & Vocational training: $22(8.3 \%)$ \\
\hline & Education: $5(1.9 \%)$ \\
\hline & Day service: 60 (22.6\%) \\
\hline & No daytime engagement: 102 (38.5\%) \\
\hline Epilepsy & $57(21.5 \%)$ \\
\hline \multirow[t]{6}{*}{ Psychiatric condition } & 70 (26.4\%) including: \\
\hline & Depression: 31 (11.7\%) \\
\hline & Schizophrenia: 18 (6.8\%) \\
\hline & Affective Disorder 10 (3.8\%) \\
\hline & Psychotic condition 8 (3\%) \\
\hline & Neurosis $3(1.1 \%)$ \\
\hline
\end{tabular}


Table 2.The prevalence of medication use by ATC category.

\begin{tabular}{|c|c|c|c|}
\hline ATC section Category & ATC four digit category & $\begin{array}{l}\begin{array}{l}\text { Number of participants } \\
\text { (range) }\end{array} \\
\end{array}$ & $\%$ of participants \\
\hline \multirow[t]{21}{*}{ N - Nervous System } & & $138(0-5)$ & 52.07 \\
\hline & Psychotropic Medication & $100(0-5)$ & 37.73 \\
\hline & Anticholinergic agents NO4A & $25(0-1)$ & 9.43 \\
\hline & AntiPsychotic N05A & $58(0-3)$ & 21.89 \\
\hline & $\begin{array}{c}\text { First } \\
\text { Antipsychotic }\end{array}$ & $21(0-3)$ & 7.92 \\
\hline & $\begin{array}{l}\text { Second generation } \\
\text { Antipsychotic }\end{array}$ & $40(0-1)$ & 15.09 \\
\hline & $\begin{array}{l}\text { Drugs for mania and } \\
\text { hypomania Anti-psychotic }\end{array}$ & $5(0-1)$ & 1.89 \\
\hline & Anxiolytics N05B & $11(0-1)$ & 4.15 \\
\hline & $\begin{array}{l}\text { Hypnotics and sedatives } \\
\text { N05C }\end{array}$ & $17(0-1)$ & 6.42 \\
\hline & AntiDepressants N06A & $46(0-2)$ & 17.36 \\
\hline & SSRI AntiDepressants & $34(0-2)$ & 12.83 \\
\hline & Tricyclic Antidepressants & $5(0-1)$ & 1.89 \\
\hline & Other Antidepressants & $9(0-1)$ & 3.40 \\
\hline & Psychostimulants N06B & $1(0-1)$ & 0.38 \\
\hline & $\begin{array}{l}\text { Antiepileptic's as Mood } \\
\text { stabilisers N03A }\end{array}$ & $7(0-1)$ & 2.64 \\
\hline & Analgesia N02A/B/C & $14(0-2)$ & 5.28 \\
\hline & $\begin{array}{l}\text { Antiepileptics for nerve pain } \\
\text { N03A }\end{array}$ & $3(0-1)$ & 1.13 \\
\hline & $\begin{array}{l}\text { Antiepileptics for epilepsy } \\
\text { N03A }\end{array}$ & $57(0-4)$ & 21.51 \\
\hline & Dopaminergic agents N04B & $2(0-2)$ & 0.75 \\
\hline & Anti-dementia drugs N06D & $3(0-1)$ & 1.13 \\
\hline & $\begin{array}{l}\text { Drugs used in Nicotine } \\
\text { dependence N07B }\end{array}$ & $1(0-1)$ & 0.38 \\
\hline $\begin{array}{l}\text { A - Alimentary tract and } \\
\text { metabolism }\end{array}$ & & $83(0-5)$ & 31.32 \\
\hline $\begin{array}{l}\text { B- Blood and blood forming } \\
\text { organs }\end{array}$ & & $26(0-3)$ & 9.81 \\
\hline C- Cardiovascular system & & $40(0-4)$ & 15.09 \\
\hline D - Dermatologicals & & $16(0-2)$ & 6.04 \\
\hline $\begin{array}{l}\text { G - Genito-urinary system } \\
\text { and sex hormones }\end{array}$ & & $30(0-2)$ & 11.32 \\
\hline $\begin{array}{l}\mathrm{H} \text { - Systemic hormonal } \\
\text { preparations }\end{array}$ & & $24(0-2)$ & 9.06 \\
\hline $\begin{array}{l}\mathrm{J} \text { - Antiinfectives for systemic } \\
\text { use }\end{array}$ & & $16(0-1)$ & 6.04 \\
\hline $\begin{array}{l}\mathrm{L}-\text { Antineoplastic and } \\
\text { immunomodulating agents }\end{array}$ & & $2(0-1)$ & 0.75 \\
\hline M - Musculo-skeletal system & & $20(0-2)$ & 7.55 \\
\hline R - Respiratory System & & $24(0-4)$ & 9.06 \\
\hline S - Sensory organs & & $5(0-1)$ & 1.89 \\
\hline V - Various & & $6(0-1)$ & 2.26 \\
\hline
\end{tabular}


* No participant was using $\mathrm{P}$ - Antiparasitic products, insecticides and repellents

Table 3. Chi square analysis of the association between challenging behaviour and medication use.

\begin{tabular}{|c|c|c|c|}
\hline & $\begin{array}{l}\text { Psychotropic } \\
\text { Medication }\end{array}$ & $\begin{array}{l}\text { Antipsychotic } \\
\text { Medication }\end{array}$ & $\begin{array}{c}\text { Antidepressant } \\
\text { Medication }\end{array}$ \\
\hline $\begin{array}{l}\text { Challenging Behaviour } \\
\text { (\%): }\end{array}$ & 56.3 & 39.6 & 18.8 \\
\hline $\begin{array}{l}\text { No Challenging } \\
\text { behaviour (\%): }\end{array}$ & 33.6 & 18 & 17.1 \\
\hline Chi Square: & $\chi^{2}(1)=8.55, p=.003$ & $\chi^{2}(1)=10.74, p=.001$ & $\chi^{2}(1)=0.08, p=.778$ \\
\hline $\begin{array}{l}\text { Aggressive Destructive } \\
\text { Behaviour (\%): }\end{array}$ & 63.6 & 36.4 & 27.3 \\
\hline $\begin{array}{l}\text { No Aggressive } \\
\text { Destructive Behaviour } \\
\text { (\%): }\end{array}$ & 35.4 & 20.6 & 16.5 \\
\hline Chi Square: & $\chi^{2}(1)=6.85, p=.009$ & $\chi^{2}(1)=2.94, p=.086$ & $\chi^{2}(1)=1.64, p=.200$ \\
\hline $\begin{array}{l}\text { Self-injurious } \\
\text { Behaviour (\%): }\end{array}$ & 70 & 50 & 25 \\
\hline $\begin{array}{l}\text { No Self-injurious } \\
\text { Behaviour (\%): }\end{array}$ & 35.1 & 19.6 & 16.7 \\
\hline Chi Square: & $\chi^{2}(1)=9.58, p=.002$ & $\chi^{2}(1)=10.00, p=.002$ & $\chi^{2}(1)=0.88, p=.348$ \\
\hline $\begin{array}{l}\text { Stereotypical } \\
\text { Behaviour (\%): }\end{array}$ & 48.3 & 37.9 & 6.9 \\
\hline $\begin{array}{l}\text { No Stereotypical } \\
\text { Behaviour (\%): }\end{array}$ & 36.4 & 19.9 & 18.6 \\
\hline Chi Square: & $\chi^{2}(1)=1.54, p=.215$ & $\chi^{2}(1)=4.90, p=.027$ & $\chi^{2}(1)=2.48, p=.115$ \\
\hline
\end{tabular}


Table 4. Association of psychotropic and antipsychotic medication use with participant sociodemographic and clinical characteristics (Unadjusted RR).

\begin{tabular}{|c|c|}
\hline \multicolumn{2}{|c|}{ Psychotropic medication } \\
\hline & Unadjusted RR (95\%Cl; p=) \\
\hline Challenging behaviour & $1.921(1.328$ to $2.781 ; p=.001)$ \\
\hline Psychiatric disorder & $4.22(3.007$ to $5.92 ; p<.001)$ \\
\hline Male gender & $1.312(.91$ to $1.892 ; p=.145)$ \\
\hline Paid / congregate care & $2.015(1.378$ to $2.946 ; p<.001)$ \\
\hline Severe / profound ID & $1.475(1.009$ to $2.155 ; p=.045)$ \\
\hline Age & $1.034(1.025$ to $1.044 ; p<.001)$ \\
\hline Sensory impairment & $1.134(.696$ to $1.848 ; p=.615)$ \\
\hline Low communication skills & $.984(.581$ to $1.668 ; p=.953)$ \\
\hline \multicolumn{2}{|c|}{ Antipsychotic medication } \\
\hline & Unadjusted RR (95\%Cl; p=) \\
\hline Challenging behaviour & $2.99(1.524$ to $5.869 ; p=.001)$ \\
\hline Psychiatric disorder & $7.478(3.945$ to $14.174 ; p<.001)$ \\
\hline Male gender & $2.42(1.311$ to $4.466 ; p=.005)$ \\
\hline Paid / congregate care & $2.516(1.363$ to $4.644 ; p=.003)$ \\
\hline Severe / profound ID & $2.099(1.096$ to $4.019 ; p=.025)$ \\
\hline Age & $1.05(1.03$ to $1.071 ; p<.001)$ \\
\hline Sensory impairment & $1.127(.501$ to $2.539 ; p=.772)$ \\
\hline Low communication skills & $.956(.392$ to $2.328 ; p=.920)$ \\
\hline
\end{tabular}

Table 5. Association of psychotropic and antipsychotic medication use with participant sociodemographic and clinical characteristics (Adjusted RR).

Psychotropic medication

\begin{tabular}{|c|c|}
\hline $\begin{array}{l}\text { Challenging behaviour } \\
\text { Psychiatric disorder } \\
\text { Paid / congregate care } \\
\text { Severe / profound ID } \\
\text { Age }\end{array}$ & $\begin{array}{l}\text { Adjusted RR (95\%Cl; } p=) \\
1.565(1.074 \text { to } 2.282 ; p=.02) \\
3.725(2.68 \text { to } 5.178 ; p<.001) \\
1.542(1.082 \text { to } 2.196 ; p=.016) \\
.926(.627 \text { to } 1.367 ; p=.699) \\
1.023(1.013 \text { to } 1.034 ; p<.001)\end{array}$ \\
\hline \multicolumn{2}{|c|}{ Antipsychotic medication } \\
\hline $\begin{array}{l}\text { Challenging behaviour } \\
\text { Psychiatric disorder } \\
\text { Male gender } \\
\text { Paid / congregate care } \\
\text { Severe / profound ID } \\
\text { Age }\end{array}$ & $\begin{array}{l}\text { Adjusted } \boldsymbol{R} \boldsymbol{R}(95 \% \mathrm{Cl} ; \mathrm{p}=) \\
2.968(1.131 \text { to } 7.79 ; \mathrm{p}=.027) \\
9.124(4.151 \text { to } 20.058 ; \mathrm{p}<.001) \\
3.35(1.573 \text { to } 7.134 ; \mathrm{p}=.002) \\
1.096(.774 \text { to } 4.698 ; \mathrm{p}=.161) \\
1.131(.427 \text { to } 2.998 ; \mathrm{p}=.804) \\
1.043(1.018 \text { to } 1.069 ; p=.001)\end{array}$ \\
\hline
\end{tabular}

